\title{
Biology of Human Aging and Recent Nutrition Therapy
}

Hiroshi Bando ${ }^{1,2^{*}}$, Koji Ebe ${ }^{2,3}$ and Masahiro Bando ${ }^{4}$

${ }^{1}$ Medical Research, Tokushima University, Tokushima, Japan

2 Japan Low Carbohydrate Diet Promotion Association, Kyoto, Japan

${ }^{3}$ Takao Hospital, Kyoto, Japan

${ }^{4}$ Department of Nutrition and Metabolism, Institute of Biomedical Sciences, Tokushima University Graduate School, Tokushima, Japan

*Corresponding author: Bando H, Medical Research, Tokushima University, Nakashowa 1-61, Tokushima 770-0943, Japan, Tel: +81-90-3187-2485; E-mail: pianomed@bronze.ocn.ne.jp

Received date: January 15, 2018; Accepted date: January 17, 2018; Published date: January 24, 2018

Copyright: @ 2018 Bando $\mathrm{H}$, et al. This is an open-access article distributed under the terms of the Creative Commons Attribution License, which permits unrestricted use, distribution, and reproduction in any medium, provided the original author and source are credited.

\begin{abstract}
Discussion concerning Calorie Restriction (CR) and low carbohydrate diet (LCD) has continued for years. Authors have developed research of LCD using super LCD with $12 \%$ of carbohydrate. The biology of human aging includes study between human and mammalian such as mice, rhesus monkeys. Moderate CR reduced age-related mortality, incidence of diabetes, cancer, cardiovascular disease. By very low calorie diet (VLCD), body weight can be reduced, but the diabetic pathological state remains. Besides CR and LCD, Zone, Ornish, LEARN Diets and Mediterranean style can be applicable. There are very low-carbohydrate ketogenic diet (VLCKD), Moderate-LCD, HighCarbohydrate Diet, as related with the definition of LCD. Morbus (M) value was investigated for clinical practice of $L C D$, in which $M$ value was remarkably improved by LCD treatment.
\end{abstract}

Keywords: Low carbohydrate diet (LCD); Morbus value (M value); Type 2 diabetes mellitus (T2DM); Calorie restriction (CR); Anti-aging medicine

Abbreviations: LCD: Low-Carbohydrate Diet; CR: CalorieRestricted; T2DM: Type 2 Diabetes Mellitus; M Value: Morbus Value; MAGE: Mean Amplitude of Glycemic Excursions; VLCD: Very Low Calorie Diet; ADA: American Diabetes Association; VLCKD: Very Low-Carbohydrate Ketogenic Diet

\section{Introduction}

Regarding nutritional therapy for metabolic and diabetic patients, the discussion has been continued for long concerning Calorie Restriction (CR) and low carbohydrate diet (LCD). Several investigators recently revealed the predominant efficacy of LCD compared with CR [1-3]. In western countries, Bernstein and Atkins originally launched LCD $[4,5]$, which was effective and striking treatment at that time. After that, LCD has been more prevalent with the several efficacy in clinical practice [6-8].

On contrast, in Japan, authors and colleagues have started LCD and developed clinical research related with $\operatorname{LCD}[9,10]$. We reported the significant role of ketone bodies in LCD and in physiological role of pregnant female and fetus-newborn axis [11]. We also continued medical and social development of LCD through Japan LCD promotion association, we proposed 3 types of actual LCD meal in daily life, which are petit, standard and super LCD [12].

\section{Biology of Human and Animals in CR}

The biology of human aging includes several investigation for anatomical, physiological and clinical similarities between human and other experimental materials and animals. They include yeast, worms, flies, mice, dogs, pigs, monkeys, and so on. Especially, some kinds of mammalian are recommended for its similarity with human.

Anti-aging medicine investigates and searches for speed against aging. From this viewpoint, discussion was found for years as to whether the lifespan is extended or the aging is delayed by CR. Among them, there are famous reports of rhesus monkeys over 20 years [13].

As a result, moderate $\mathrm{CR}$ reduced age-related mortality. In particular, CR reduced the incidence of diabetes, cancer, cardiovascular disease and cerebral atrophy. In comparison with control and CR group, the incidences of both neoplasia and cardiovascular disease was reduced by $50 \%$. Especially, improvement in insulin sensitivity conferred by $\mathrm{CR}$, has been consistent and remarkable [14,15]. Improved glucose homeostasis was maintained, inducing that diabetes was prevented by CR. Out of 38 control monkeys, 5 diabetes and 11 pre-diabetics were observed. In contrast, all animals on CR group revealed no glucose impairment. From these data, CR would possibly make aging slower in a primate species.

Humans are classified in the category of primates. Therefore, in medical research, it is expected that the results and information obtained by monkeys will be found in man as well. From the viewpoint of molecular biology, is that true in all cases? Lots of research have found concerning several experimental animals.

Transcriptional patterns of CR-animals suggest that CR retards the aging process by causing a metabolic shift toward increased protein turnover and decreased macromolecular damage [16]. The increase in longevity by dietary $\mathrm{CR}$ is coupled to profound beneficial effects on age-related pathology [17]. There is the reverse relationship between calorie intake and increase of lifespan in mice, suggesting a role for regulators of energy metabolism in the mechanism of CR. Consequently, metabolic reprogramming by induction of CR may be a crucial point in the mechanism for the extension of life span [13]. Investigations of yeast, worms, flies and mice would indicate a certain 
role for nutrient which is responsive signaling molecules including SIRT1, mTOR and PGC-1 $\alpha$ in aging and CR [18]. How are these findings related to the aging mechanism? The conservation of the effects of CR would depend on aging in primates.

Based on the above circumstances, attention was paid to whether the effects in monkeys could be seen in humans as well. A multicenter study involving 16 large facilities in the United States was conducted. Look AHEAD Research Group reported the results of multicenter study [19]. They included 5145 overweight or obese patients with type 2 diabetes mellitus (T2DM) and followed up 13.5 years. As a result, intensive lifestyle intervention focusing on weight loss did not reduce the rate of cardiovascular events.

Furthermore, the negative effect on musculoskeletal system [20] suggested in rhesus monkeys has also been confirmed in humans [21]. From the above, it is time to need a scientific re-evaluation on the effectiveness and safety of CR.

\section{CR and VLCD}

There was an impressive report showing the effectiveness and limit of Very Low Calorie Diet (VLCD) [22,23]. It shows the results of first 6 months from the Newcastle University to the British Diabetes Association Institute magazine [22] and several years' data [23] to the American Diabetes Association Diabetes Care. The protocol of the study is a long-term study in which 15 patients with type 2 diabetes carry VLCD for 2 months and CR for 6 months. Optifast ${ }^{\oplus} 624 \mathrm{kcal} /$ day ( $P F C=34: 19.5: 43$ ) was used for VLCD and then gradually increased the caloric intake. The judgment of remission of diabetes was less than 126 $\mathrm{mg} / \mathrm{dL}$ of fasting blood glucose [22,23]. As a result of short-term vs long-term patients, body weight change and remission rate were of $99.0 \rightarrow 84.5 \mathrm{~kg}$, vs $96.9 \rightarrow 83.0 \mathrm{~kg}, 86.7 \%$ vs $50.0 \%$, respectively. In the latter, the fasting blood glucose did not decrease enough.

This study seems to suggest implications for diabetic diet therapy in the future. American Diabetes Association (ADA) previously mentioned the optimization of calorie as the most important task, because its aim was to acquire ideal weight [24]. In the countries where T2DM develops after obesity such as United States, eliminating obesity could be thought to decrease T2DM. Meanwhile, ADA stated in 2004 that CR diet cannot be maintained for a long time [25], and monitoring glucose intake has now become regarded as an important issue $[26,27]$.

By this study, weight loss effect of VLCD became clear. However, even if the weight improves, the pathological diabetic state remains. Although visceral fat area drastically decreases and hepatic insulin resistance improves, elevated blood glucose persists. One of the cause is the continuation of intake for carbohydrates. Furthermore, it is not easy to actually live 8 weeks with a meal less than $700 \mathrm{Kcal}$ a day. From the above, it would be rather difficult to aim for standard weight in application of CR.

\section{Progress in LCD}

After Atkins an Bernstein started LCD [4,5], several impressive research were reported. Atkins, Zone, Ornish and LEARN Diets were compared as well-known four dietary regimens [28]. Similary, Atkins, South Beach, Weight Watchers and Zone diets were also compared [29]. After that, Dietary Intervention Randomized Controlled Trial (DIRECT) group reported the efficacy of the LCD up to 2 years [6], and up to 6 year [7]. The effect of LCD plus Mediterranean-style diet was introduced with efficacy [30], which might be one of the better option in the future.

Formerly, the definition of LCD was rather vague. The effect of LCD over the years has been summarized, according to the percentage of carbohydrates [31,32]. Suggested definitions for different forms of LCD are shown in Table 1, which are very low-carbohydrate ketogenic diet (VLCKD), LCD, Moderate-LCD, High-Carbohydrate Diet [31-33].

\section{Very low-carbohydrate ketogenic diet (VLCKD)}

Carbohydrate, $20-50 \mathrm{~g} /$ day or $<10 \%$ of the $2000 \mathrm{kcal} / \mathrm{d}$ diet, whether or not ketosis occurs. Derived from levels of carbohydrate required to induce ketosis in most people.

Recommended early phase ("induction") of popular diets such as Atkins Diet or Protein Power.

Low-carbohydrate diet: $<130 \mathrm{~g} /$ day or $<26 \%$ total energy

The ADA definition of $130 \mathrm{~g} /$ day as its recommended minimum.

Moderate-Carbohydrate Diet: $26 \%-45 \%$

Upper limit, approximate carbohydrate intake before the obesity epidemic (43\%).

High-Carbohydrate Diet: $>45 \%$

Recommended target on ADA websites.

The 2010 Dietary Guidelines for Americans recommends 45\%-65\% carbohydrate. The average American diet is estimated to be w49\% carbohydrate.

Carbohydrate Consumption (NHANES).

Table 1: Suggested definitions for different Forms of low-carbohydrate diets [31-33]. (ADA: American Diabetes Association; NHANES: National Health and Nutrition Examination Survey; NHANES is a series of studies conducted since 1960 that monitors $>5000$ people. The content of this table is from some reports). 
JAMA published the US dietary guidelines (the 2015 US dietary guidelines) [34]. In the guideline, an accurate revision of the Dietary Guidelines is crucial to the health of millions of people. Integral to this process is the Dietary Guidelines Advisory Committee (DGAC) report.

\section{Research in LCD}

In Japan, there are long history of CR and recent LCD treatment, because rice is our staple food for long years. Then, we can treat diabetic patients for CR or LCD and compare the treatment of inpatients and also out-patients.

Indeed, we have experienced many cases that blood glucose control improves with calorie restriction. However, its successful reason is that the disease duration is short and CR improves pancreatic first phase insulin secretion. Since active exercise therapy is also carried out in education hospitalization, insulin sensitivity of muscles will be improved even more [35]. On the other hand, patients with long duration would not have so effective results in CR treatment.

Furthermore, in the case of Japanese early diabetics, the mean BMI at onset is 24.4 and there are not many cases of obesity combined [36]. For even Japanese diabetics in early stages, will CR diets be really the first choice? Instead, LCD seems to be recommended because blood glucose would not be so increased.

The process for LCD development until now in Japan would be summarized as follows. The authors and collaborators launched the LCD $[9,10]$ and NIPPON DATA 80 (National Integrated Project for Prospective observation of Non-communicable Disease and its Trends in the Aged 1980) reported 29 year data concerning the effect of LCD [37]. A research on RCT for mild restriction of glucose $130 \mathrm{~g} /$ day was reported [38]. Furthermore, we reported research of LCD with hypertriglyceridemia [39], with hyperketonemia in the axis of fetusplacenta-newborn-pregnant women [11], with renal function [40], with lifestyle habits [41], and so on.

In addition, super-LCD with $12 \%$ of carbohydrate has reduced blood glucose and $\mathrm{M}$ value in short period [39,40,42]. Morbus (M) value is the index which represents both blood sugar level and mean amplitude of glycemic excursions (MAGE) $[43,44]$.

$M$ value is calculated by the following formula: $M=M B S+M W$, where $\mathrm{MW}=($ maximum blood glucose-minimum glucose $) / 20$; MBS=The mean of MBSBS; MBSBS=Individual M-value for each blood glucose value calculated as (absolute value of $(10 \times \log$ (blood glucose value/120)) $)^{3}$.

$$
M-\text { value } \frac{\sum}{N}\left|M \frac{B S}{B S}\right|+W / 20 \quad M \frac{B S}{B S}=\left|10 \log \frac{P G}{120}\right|^{3}
$$

Regarding glucose variability, daily profiles of blood glucose has been measured 7 times a day, which data were calculated into average glucose and $M$ value. Similar results were found on 7 times or 20 times of sampling per day $[45,46]$. It also revealed similar results compared with the continuous glucose monitoring (CGM) [47,48].

Daily profile of blood glucose and $\mathrm{M}$ value were investigated in 2 patients with T2DM [39,40,42] (Figure1).

The protocol was measuring glucose on day $0,2,12$ from the start of LCD. There were remarkable decrease in glucose and $M$ value by LCD $[39,40,42]$.

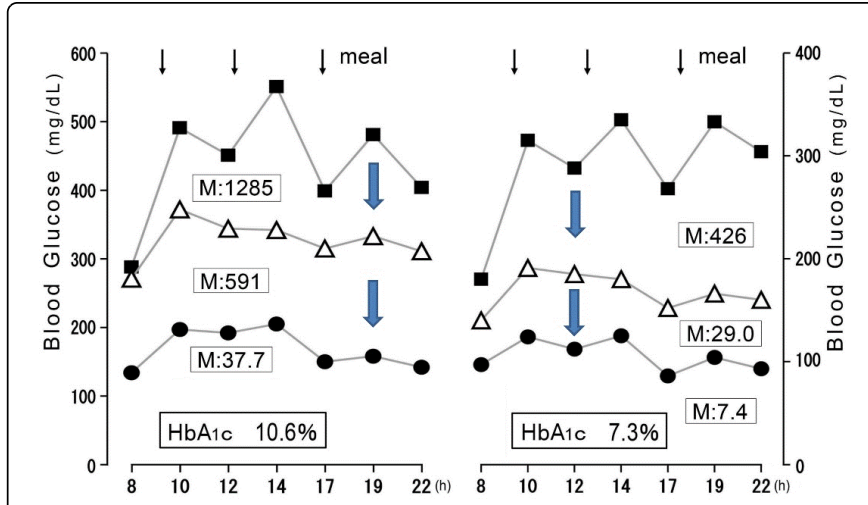

Figure 1: The profile of blood glucose and $M$ value.

\section{Conclusion}

In summary, research on human and animal biology has continued for years. Among them, research on anti-aging medicine from gene expression to clinical practice has been remarkable for extension of life span. In fact, the importance of nutrition is becoming apparent, and it seems to be useful for improving people's health and lifespan.

\section{References}

1. Mansoor N, Vinknes KJ, Veierød MB, Retterstøl K (2016) Effects of lowcarbohydrate diets v. low-fat diets on body weight and cardiovascular risk factors: A meta-analysis of randomised controlled trials. Br J Nutr 115: 466-479.

2. Dehghan M, Mente A, Zhang X, Swaminathan S, Li W, Mohan V, et al. (2017) Associations of fats and carbohydrate intake with cardiovascular disease and mortality in 18 countries from five continents (PURE): A prospective cohort study. Lancet 17: 32252-32253.

3. Kwon YJ, Lee HS, Le JW (2017) Association of carbohydrate and fat intake with metabolic syndrome. Clin Nutr 17: 30233-30239.

4. Atkins R (1998) Dr. Atkins' new diet revolution, Rev edn. Avon books, New York.

5. Bernstein RK (2007) Dr. Bernstein's diabetes solution: The complete guide to achieving normal blood sugars. Little, Brown US, New York.

6. Shai I, Schwarzfuchs D, Henkin Y, Shahar DR, Witkow S, et al. (2008) Dietary intervention randomized controlled trial (direct) group weight loss with a low-carbohydrate, mediterranean, or low-fat diet. $\mathrm{N}$ Engl J Med 359: 229-241.

7. Schwarzfuchs D, Golan R, Shai I (2012) Four-year follow-up after twoyear dietary interventions. N Engl J Med 367: 1373-1374.

8. Gower BA, Boss AM (2014) A lower-carbohydrate, higher-fat diet reduces abdominal and intermuscular fat and increases insulin sensitivity in adults at risk of type 2 diabetes. J Nutr 145: 177S-183S.

9. Ebe K, Ebe Y, Yokota S, Matsumoto T, Hashimoto M, et al. (2004) Low carbohydrate diet (LCD) treated for three cases as diabetic diet therapy. Kyoto Med Assoc J 51: 125-129.

10. Bando H, Nakamura $\mathrm{T}$ (2008) Carbo-count therapy and low carbohydrate diet (LCD). J Ther 90: 3105-3111.

11. Muneta T, Kawaguchi E, Nagai Y, Matsumoto M, Ebe K, et al. (2016) Ketone body elevation in placenta, umbilical cord, newborn and mother in normal delivery. Glycative Stress Res 3: 133-140.

12. Bando H, Ebe K, Muneta T, Bando M, Yonei Y (2017) Clinical effect of low carbohydrate diet (LCD): Case report. Diabetes Case Rep 2: 124.

13. Colman RJ, Anderson RM, Johnson SC, Kastman EK, Kosmatka KJ, et al. (2009) Caloric restriction delays disease onset and mortality in rhesus monkeys. Science 325: 201-204. 
14. Ramsey JJ, Colman RJ, Binkley NC, Christensen JD, Gresl TA, et al. (2000) Dietary restriction and aging in rhesus monkeys: The University of Wisconsin study. Exp Gerontol 35: 1131-1149.

15. Gresl TA, Colman RJ, Roecker EB, Havighurst TC, Huang Z, et al. (2001) Dietary restriction and glucose regulation in aging rhesus monkeys: A follow-up report at 8.5 years. Am J Physiol Endocrinol Metab 281: E757-765.

16. Lee CK, Klopp RG, Weindruch R, Prolla TA (1999) Gene expression profile of aging and its retardation by caloric restriction. Science 285 1390-1393.

17. Mair W, Dillin A (2008) Aging and survival: the genetics of life span extension by dietary restriction. Annu Rev Biochem 77: 727-754.

18. Anderson RM, Weindruch R (2007) Metabolic reprogramming in dietary restriction. Interdiscip Top Gerontol 35: 18-38.

19. Look AHEAD Research Group; Wing et al. (2013) Cardiovascular effects of intensive lifestyle intervention in type 2 diabetes. N Engl J Med 369: $145-54$.

20. Colman RJ, Beasley TM, Allison DB, Weindruch R (2012) Skeletal effects of long-term caloric restriction in rhesus monkeys. Age (Dordr) 34: 1133-1143.

21. Lipkin EW, Schwartz AV, Anderson AM, Davis C, Johnson KC, et al. (2014) The Look AHEAD Trial: bone loss at 4 year follow-up in type 2 diabetes. Diabetes Care 37: 2822-2829.

22. Steven S, Taylor R (2015) Restoring normoglycaemia by use of a very low calorie diet in long- and short-duration type 2 diabetes. Diabet Med 32: 1149-1155.

23. Steven S, Hollingsworth KG, Al-Mrabeh A, Avery L, Aribisala B, et al. (2016) Very low-calorie diet and 6 months of weight stability in type 2 diabetes: Pathophysiological changes in responders and non-responders. Diabetes Care 39: 808-815.

24. Bierman EL, Albrink MJ, Arky RA, Connor WE, Dayton S, et al. (1971) Principles of nutrition and dietary recommendations for patients with diabetes mellitus. Diabetes. 20: 633-634.

25. Franz MJ, Bantle JP, Beebe CA, Brunzell JD, Chiasson JL, et al. (2004) Nutrition principles and recommendations in diabetes. Diabetes Care 27: S36-S46.

26. Bantle JP, Wylie-Rosett J, Albright AL, Apovian CM, Clark NG, et al. (2008) Nutrition recommendations and interventions for diabetes: a position statement of the American Diabetes Association. Diabetes Care 31: S61-S78.

27. Evert AB, Boucher JL, Cypress M, Dunbar SA, Franz MJ, et al. (2013) Nutrition therapy recommendations for the management of adults with diabetes. Diabetes Care 36: 3821-3842.

28. Gardner CD, Kiazand A, Alhassan S, Kim S, Stafford RS, et al. (2007) Comparison of the Atkins, Zone, Ornish and LEARN diets for change in weight and related risk factors among overweight premenopausal women the A to Z weight loss study: A randomized trial. JAMA 297: 969-77.

29. Atallah R, Filion KB, Wakil SM, Genest J, Joseph L, et al. (2014) Longterm effects of 4 popular diets on weight loss and cardiovascular risk factors: A systematic review of randomized controlled trials. Circ Cardiovasc Qual Outcomes 7: 815-827.

30. Esposito K, Maiorino MI, Ciotola M, Di Palo C, Scognamiglio P, et al. (2009) Effects of a Mediterranean-style diet on the need for antihyperglycemic drug therapy in patients with newly diagnosed type 2 diabetes: A randomized trial. Ann Intern Med 151: 306-314.

31. Feinman RD, Pogozelski WK, Astrup A. Bernstein RK, Fine EJ, et al. (2015) Dietary carbohydrate restriction as the first approach in diabetes management: Critical review and evidence base. Nutrition. 31: 1-13.

32. American Diabetes Association (2013) Nutrition recommendations and interventions for diabetes-2013. Diabetes Care 36: S12-S32.

33. Accurso A, Bernstein RK, Dahlqvist A, Draznin B, Feinman RD, et al. (2008) Dietary carbohydrate restriction in type 2 diabetes mellitus and metabolic syndrome: Time for a critical appraisal. Nutr Metab 5: 9.

34. Mozaffarian D, Ludwig DS (2015) The 2015 US dietary guidelines: Lifting the ban on total dietary fat. JAMA 313: 2421-2422.

35. Yokoyama H, Emoto M, Araki T, Fujiwara S, Motoyama K, et al. (2004) Effect of aerobic exercise on plasma adiponectin levels and insulin resistance in type 2 diabetes. Diabetes Care 27: 1756-1758.

36. Heianza Y, Arase Y, Kodama S, Tsuji H, Tanaka S, et al. (2015) Trajectory of body mass index before the development of type 2 diabetes in Japanese men: Toranomon Hospital Health Management Center Study. J Diabetes Investig 6: 289-294.

37. Nakamura Y, Okuda N, Okamura T, Kadota A, Miyagawa N, et al. (2014) Low-carbohydrate diets and cardiovascular and total mortality in Japanese: A 29 year follow-up of NIPPON DATA80. Br J Nutr 28:112: 916-924.

38. Sato J, Kanazawa A, Makita S, Hatae C, Komiya K, et al. (2017) A randomized controlled trial of $130 \mathrm{~g} /$ day low-carbohydrate diet in type 2 diabetes with poor glycemic control. Clin Nutr 36: 992-1000.

39. Ebe K, Bando H, Muneta T, Bando M, Yonei Y (2017) Effect of low carbohydrate diet (LCD) for diabetic patients with hypertriglycemia. Endocrinol Metab 1: 104.

40. Bando H, Ebe K, Muneta T, Bando M, Yonei Y (2017) Investigation of uric acid and cystatin $\mathrm{C}$ on low-carbohydrate diet (LCD). Diabetes Res Open J 3: 31-38.

41. Ebe K, Bando H, Yamamoto K, Bando M, Yonei Y (2018) Daily carbohydrate intake correlates with HbA1c in low carbohydrate diet (LCD). J Diabetol 1: 4-9.

42. Bando H, Ebe K, Muneta T, Bando M, Yonei Y (2017) Effect of low carbohydrate diet on type 2 diabetic patients and usefulness of M-value. Diabetes Res Open J 3: 9-16.

43. Schlichtkrull J, Munck O, Jersild M (1965) The M-value, an index of blood sugar control in diabetics. Acta Med Scand 177: 95-102.

44. Moberg E, Kollind M, Lins PE, Adamson U (1993) Estimation of bloodglucose variability in patients with insulin-dependent diabetes mellitus. Scand J Clin Lab Invest 53: 507-514.

45. Siegelaar SE, Holleman F, Hoekstra JBL Devries JH (2010) Glucose variability: Does it matter? Endocr Rev 31: 171-182.

46. Monnier L, Colette C (2011) Glycemic variability: Can we bridge the divide between controversies? Diabetes Care 34: 1058-1059.

47. Service FJ (2013) Glucose variability. Diabetes 62: 1398-1404.

48. Baghurst P (2011) Calculating the mean amplitude of glycemic excursion from continuous glucose monitoring data: An automated algorithm. Diabetes Technol Ther 13: 296-302. 